Research article

Open Access

\title{
Increased copy number at 3p14 in breast cancer
}

\author{
Ingrid Ljuslinder ${ }^{1}$, Beatrice Malmer ${ }^{1}$, Irina Golovleva ${ }^{2}$, Marcus Thomasson ${ }^{1}$, Kjell Grankvist ${ }^{3}$, \\ Thomas Höckenström ${ }^{4}$, Stefan Emdin ${ }^{5}$, Yvonne Jonsson ${ }^{1}$, Håkan Hedman ${ }^{1}$ and Roger Henriksson ${ }^{1}$
}

\author{
1Department of Radiation Sciences, Oncology, Umeå University, Umeå, Sweden \\ 2Department of Medical Biosciences, Medical and Clinical Genetics, Umeå, Sweden \\ ${ }^{3}$ Department of Medical Biosciences, Clinical Chemistry, Umeå University, Umeå, Sweden \\ ${ }^{4}$ Department of Pathology, Umeå University, Umeå, Sweden \\ ${ }^{5}$ Department of Surgical and Perioperative Sciences, Division of Surgery, Umeå University, Sweden \\ Corresponding author: Ingrid Ljuslinder, ingrid.ljuslinder@onkologi.umu.se
}

Received: 12 Nov 2004 Revisions requested: 4 Apr 2005 Revisions received: 2 May 2005 Accepted: 8 Jun 2005 Published: 6 Jul 2005

Breast Cancer Research 2005, 7:R719-R727 (DOI 10.1186/bcr1279)

This article is online at: http://breast-cancer-research.com/content/7/5/R719

(C) 2005 Ljuslinder et al.; licensee BioMed Central Ltd.

This is an Open Access article distributed under the terms of the Creative Commons Attribution License (http://creativecommons.org/licenses/by/

2.0), which permits unrestricted use, distribution, and reproduction in any medium, provided the original work is properly cited.

\begin{abstract}
Introduction The present study was conducted to investigate if chromosome band 3p14 is of any pathogenic significance in the malignant process of breast cancer. Genetic studies have implicated a tumour suppressor gene on chromosome arm $3 p$ and we have proposed $L R I G 1$ at $3 p 14$ as a candidate tumour suppressor. The $L R / G 1$ gene encodes an integral membrane protein that counteracts signalling by receptor tyrosine kinases belonging to the ERBB family. LRIG1 mRNA and protein are expressed in many tissues, including breast tissue.
\end{abstract}

Methods In the present report we analysed the $L R / G 1$ gene by fluorescence in situ hybridisation (FISH), LRIG1 mRNA by quantitative RT-PCR, and LRIG1 protein by western blot analysis. Two tumour series were analysed; one series consisted of 19 tumour samples collected between 1987 and 1995 and the other series consisted of 9 tumour samples with corresponding non-neoplastic breast tissues collected consecutively.

Results The LRIG1 gene showed increased copy number in 11 out of 28 tumours (39\%) and only one tumour showed a deletion at this locus. Increased LRIG1 copy number was associated with increased levels of LRIG1 mRNA (two of three tumours) and protein (four of four tumours) in the tumours compared to matched non-neoplastic breast tissue, as assessed by RT-PCR and western blot analysis.

Conclusion The molecular function of LRIG1 as a negative regulator of ERBB receptors questions the biological significance of increased $L R / G 1$ copy number in breast cancer. We propose that a common, but hitherto unrecognised, breast cancer linked gene is located within an amplicon containing the LRIG1 locus at 3p14.3.

\section{Introduction}

Breast cancer is a major cause of death among women. In order to provide optimal treatment, prognostic factors, such as lymph node status and steroid receptor expression, are widely used. In recent years, genetic approaches studying chromosomal aberrations have been suggested as a tool in the process to individualise the adjuvant treatment given to patients. Several studies have been published during the past years with a focus on identifying the genes that contribute to initiation and clinical progression of breast cancer $[1,2]$.
Identification of a germline mutation of $B R C A 1$ at $17 q 21$ [3] and $B R C A 2$ at $13 q 12-13$ [4] has been an important finding in studies of hereditary breast cancer. Epidermal growth factor receptor (EGFR/ERBB1) and ERBB2 (also known as HER2) overexpression [5-7], p53 inactivation [8,9] and nm23 overexpression [10] also seem to be of clinical prognostic importance. Chromosomal amplifications have been described in breast cancer for several genes, including MYC at 8q24 and $E R B B 2$ at $17 q 11.2[11,12]$. Other amplified chromosomal areas detected in breast cancer are 13q31, 17q22-24, 1q4144 and $20 q 13$. In general, gene amplifications are considered late events in cancerogenesis, even though much is still

$\overline{\mathrm{CGH}}=$ comparative genomic hybridisation; EGFR = epidermal growth factor receptor; FISH = fluorescence in situ hybridisation; LOH = loss of heterozygosity; LRIG1 = leucine-rich and immunoglobulin-like domains 1 ; PBS = phosphate buffered saline; RT-PCR = reverse transcriptase polymerise chain reaction; $\mathrm{SSC}=$ saline sodium citrate. 
unknown about the importance of amplifications of specific genes. In breast cancer, amplification of ERBB2 correlates with a worse prognosis [13] and amplification of C-MYC is associated with progression from carcinoma in situ to invasive breast cancer [14]. Cytogenetic analyses of tumours have shown that chromosome 1 is the most frequently altered chromosome in breast cancer [15]. In other breast cancer studies, loss of heterozygosity ( $\mathrm{LOH}$ ) at $3 p$ was the most common chromosomal aberration [16-18]. In a study by Maitra et al. [19], LOH in the 3p area was apparent in $87 \%$ of breast tumours, and LOH at 3p14.3 in $41 \%$ of the tumours. The short arm of chromosome 3 thus likely harbours at least one tumour suppressor gene [20]. The FHIT gene localized to 3p14.2, which frequently shows $\mathrm{LOH}$, is also suggested to be a prognostic factor in breast cancer $[21,22]$.

Recently, the human gene LRIG1 (leucine-rich and immunoglobulin-like domains 1) was described and localised to chromosome 3p14.3 [23,24]. The LR/G1 gene encodes a protein with extracellular leucine-rich repeats and immunoglobulin-like domains, a transmembrane part, and a cytoplasmic tail. LRIG1 acts as a negative regulator of ERBB1-4 by enhancing receptor ubiquitylation and degradation $[25,26]$. The mechanism involves the recruitment of c-Cbl, an E3 ubiquitin ligase that simultaneously ubiquitylates EGFR and LRIG1 and sorts them for degradation [25].

The role of LRIG1 as a part of a group of proteins that help desensitize receptor tyrosine kinase (RTK) signalling makes it important to study the expression and role of LRIG1 in tumours in which the ERBB receptors have clinical relevance.

The present study was conducted to investigate if the $L R / G 1$ gene, $\mathrm{mRNA}$, or protein was deleted or dysregulated in human breast cancer. The $L R / G 1$ locus was analysed by fluorescence in situ hybridisation (FISH), mRNA was quantified by real-time RT-PCR and protein was analysed by western blot analysis. To further explore how LRIG1 expression was related to growth factor receptor expressions, quantitative RT-PCR of EGFR and ERBB2 was performed. We report an unexpected increase in copy number of the LRIG1 locus in 39\% of the breast tumours, implicating a breast cancer gene at, or close to, 3p14.3.

\section{Materials and methods Patients and sample preparation}

Previously collected (1986 to 1995) samples from 19 patients were included in a first examination (group A). Tumour samples and non-neoplastic breast tissue were then collected from nine patients with breast carcinoma (group B). Clinical characteristics of the patients are presented in Table 1. The study was approved by the local ethics committee. None of the patients had received any treatment prior to specimen collection. In group B, samples of the tumour and a piece of the nonneoplastic breast tissue were collected immediately after exci- sion, one part of each frozen in liquid nitrogen and stored at $80^{\circ} \mathrm{C}$, and another part stored in RNAlater (Ambion inc, Austin, Texas, USA). The other adjacent parts of the tissue samples were fixed in formalin, paraffin embedded and used for routine morphological examination and tumour grading (according to Page et al. [27]), immunohistochemical staining and tumour tissue array construction. The preparation of RNA was performed as previously described [23].

\section{FISH}

Freshly frozen breast cancer tissues were disintegrated in methanol:acetic acid solution (3:1; Carnoy's solution) on ice. The nuclei were collected by passing the disintegrated tissues through a nylon mesh (pore size $70 \mu \mathrm{m}$ ) and then centrifuged. Cells were washed in methanol:acetic acid solution (3:1) two to three times at room temperature. FISH slides were prepared by dropping the cell suspension onto glass slides. After airdrying, FISH-slides were immediately used or stored at $-20^{\circ} \mathrm{C}$. Before hybridisation, FISH-slides were incubated in $75 \mathrm{mM}$ $\mathrm{KCl}$ for 20 minutes at $37^{\circ} \mathrm{C}$ and fixed in Carnoy's solution for 5 minutes at room temperature. After fixation, FISH slides were treated with RNAase $(100 \mu \mathrm{g} / \mathrm{ml})$ for $1 \mathrm{~h}$, followed by washing in $2 \times$ SSC (saline sodium citrate) three times for 2 minutes each time. Finally, the slides were incubated in solution containing $100 \mu \mathrm{g} / \mathrm{ml}$ pepsin in $10 \mathrm{mM} \mathrm{HCl}$ for 10 minutes, followed by incubation in PBS for 5 minutes at room temperature and stepwise dehydration in alcohol $(70 \%, 80 \%, 95 \%)$. The BAC clone $751 \mathrm{k} 5$ (Invitrogene, Carlsbad, USA), containing the $L R / G 1$, was used as the FISH probe. DNA was labelled by nick translation using Spectrum Orange according to the manufacturer's protocol (Abbot Diagnostics, Wiesbaden-Delkenheim, Germany). Probe (10 $\mu \mathrm{l})$ containing $100 \mathrm{ng}$ DNA, $5 \mu \mathrm{l}$ Cot-1 DNA in 60\% formamide was pre-incubated for $1 \mathrm{~h}$ at $37^{\circ} \mathrm{C}$ and then applied to each slide. Probe and target DNA were denatured simultaneously for 3 minutes at $72^{\circ} \mathrm{C}$. Slides were hybridised overnight at $37^{\circ} \mathrm{C}$ in a humidity chamber. Post-hybridisation washing was performed in $2 \times$ SSC containing $0.3 \%$ NP-40. Nuclear counterstaining was done with DAPI solution for 2 minutes. As control, a centromere probe for chromosome 3 was included in the hybridisation solution.

In each case, $L R / G 1$ and CEP3 signals were counted in 100 to 200 nuclei by two independent investigators. The presence of at least three signals in more than $20 \%$ of the nuclei was the criteria for scoring an increased copy number of $L R / G 1$. Analysis was performed using an Axioplan 2 microscope (Carl Zeiss Vision, Hallbergmoos, Germany.) Digital images were captured and stored using Cytovision software (Applied Imaging Corporation, San Jose, USA).

\section{Cell lines}

The breast cancer cell lines MDA-MB-231, MDA-MB-415 and HS 578T were obtained from American type culture collection (Manassas, VA, USA) and ZR-75-1 was kindly provided by Dr J Bergh (Uppsala University, Sweden). The breast cancer cell 
Clinical characteristics of the 28 breast tumours included in the study

\begin{tabular}{|c|c|c|c|c|}
\hline & $\mathrm{n}$ & $\%$ of total & $\begin{array}{l}\text { Tumours with increased } L R I G 1 \text { copy } \\
\text { number }(n=11)\end{array}$ & $\begin{array}{l}\text { Tumours without increased } L R / G 1 \text { copy } \\
\text { number }(\mathrm{n}=17)\end{array}$ \\
\hline \multicolumn{5}{|l|}{ Tumour type } \\
\hline Ductal & 21 & 75 & $10(82 \%)$ & $11(65 \%)$ \\
\hline Lobular & 2 & 7 & 1 & 1 \\
\hline Mixed group & 4 & 14 & 0 & 4 \\
\hline Medullar & 1 & 4 & 0 & 1 \\
\hline \multicolumn{5}{|l|}{ Axillar lymph node } \\
\hline Negative & 17 & 61 & $6(54 \%)$ & $11(65 \%)$ \\
\hline Positive & 10 & 36 & $5(45 \%)$ & $5(29 \%)$ \\
\hline Missing value & 1 & 4 & 0 & 1 \\
\hline \multicolumn{5}{|l|}{ Estrogen receptor } \\
\hline Positive & 21 & 75 & $8(73 \%)$ & $13(76 \%)$ \\
\hline Negative & 4 & 14 & $2(9 \%)$ & $2(12 \%)$ \\
\hline Missing value & 3 & 11 & 1 & $2(12 \%)$ \\
\hline \multicolumn{5}{|l|}{ Progesterone receptor } \\
\hline Positive & 18 & 64 & $6(54 \%)$ & $12(70 \%)$ \\
\hline Negative & 5 & 18 & $3(27 \%)$ & $2(28 \%)$ \\
\hline Missing value & 5 & 18 & $2(18 \%)$ & $3(18 \%)$ \\
\hline Outcome $=$ deceased & 10 & 36 & $3(27 \%)$ & $7(41 \%)$ \\
\hline
\end{tabular}

lines were cultivated in Dulbecco's modified Eagles medium, supplemented with $10 \% \mathrm{w} / \mathrm{v}$ fetal bovine serum and $50 \mu \mathrm{g} / \mathrm{ml}$ gentamicin from Invitrogen AB (Täby, Sweden). The immortalised mammary epithelial cell line hTERT-HME1 was obtained from BD Bioscencies Clontech (Stockholm, Sweden) and cultivated according to the manufacurer's instructions by using media and supplements from Clonetics, Bio Whittaker (Walkersville, MD, USA).

\section{Quantitative RNA analysis}

RNA was prepared from tissue samples by using RNAqueous kit (Ambion inc, Austin, Texas, USA), according to the manufacturer's instructions. Real-time quantitative RT-PCR was performed as previously described [28].

\section{Western blot analysis}

Cell lysates, protein concentrates and immunoprecipitated material were incubated in LDS (lithium dodecyl sulfate) sample buffer for 10 minutes at $70^{\circ} \mathrm{C}$ followed by electrophoresis on $3 \%$ to $8 \%$ TRIS-acetate NuPAGE gradient gel. The proteins were thereafter transferred to polyvinylidene difluoride membranes by using an Xcell II Mini-Gel blot module. Gel apparatus, gels, buffers, blotting module, and membranes were from Invitrogen. Non-specific binding was blocked by using incubation of the membranes with $5 \% \mathrm{w} / \mathrm{v}$ non-fat milk powder in TBS containing $0.1 \% \mathrm{w} / \mathrm{v}$ Tween-20. The membranes were thereafter incubated with the primary antibodies at $1 \mu \mathrm{g} / \mathrm{ml}$ followed by peroxidase-conjugated secondary antibodies (Amersham Pharmacia Biotech, Amersham Biosciences, New Jersey, USA). The primary antibodies used were LRIG1-151 [24] and rabbit anti-actin (Sigma-Aldrich St. Louis, Missouri, USA). Visualization was performed by using the enhanced chemiluminescense system ECL-plus, (ECLadvanced and hyperfilm ECL Blotting Detection system kit, Amersham Biosciences, New Jersey, USA). The samples were diluted stepwise by approximately $50 \%$ in 3 to 4 steps. The results were analysed visually by three separate investigators and an apparent change between tumour and non-neoplastic tissue of at least $50 \%$ was considered convincing.

\section{Results}

\section{FISH analysis of archived breast cancer samples}

To evaluate the number of $L R I G 1$ gene copies, FISH was performed on cell nuclei from the archived breast cancer samples (group A). An increased copy number of $L R / G 1$ was seen in more than $20 \%$ of the nuclei in 7 of the 19 tumours (in most cells three to five signals). The fraction of tumour cells with increased copy number varied between $23 \%$ and $79 \%$. Normal signal pattern corresponding to two copies per nucleus was detected in 11 of the 19 tumours, and 1 tumour demonstrated decreased copy number of LRIG1 (Table 2). 
Table 2

FISH analysis of the LRIG1 locus in 28 breast cancer tumours

\begin{tabular}{lcc}
\hline FISH 3p14.3 & Group A $(n=19)$ & Group B $(n=9)$ \\
\hline Increased copy number & $7(36 \%)$ & $4(44 \%)$ \\
Normal copy number & $11(57 \%)$ & $5(55 \%)$ \\
Decreased copy number & $1(5 \%)$ & 0 \\
\hline
\end{tabular}

Group A: tumours collected 1986 to 1996 retrospectively. Group B: tumours collected 2002 to 2003 prospectively.

\section{FISH Analysis of Fresh Tumour Samples and Breast Cell} lines

FISH analysis revealed increased copy numbers of LRIG1 in four of the nine tumours from group $B$ (example shown in Fig. 1a). The fraction of tumour cells with increased copy number varied between $21 \%$ and $49 \%$. Normal signal pattern corresponding to two $L R I G 1$ copies per nucleus was detected in the remaining five tumours (Table 2). A parallel FISH analysis including 10 tumours of a different tissue origin showed no aberrations of LRIG1 gene copy numbers in these tumours (ongoing study, data not shown). In one of the breast tumours with increased copy number of LRIG1 (patient B8), a more detailed FISH analysis was performed to assess the chromosome 3 status and the ploidity of the tumour cells. This showed that the LRIG1 copy number was increased (Fig. 1a) but the chromosome 3 centromere was not (Fig. 1b). Furthermore, by using a mixture of LRIG1 probe and a specific $3 p$ subtelomere probe (probe position 30 tel (D3S4559); Abbot Vysis), no increased copy number was found for the $3 p$ subtelomeric region either (Fig. 1c). No evidence of aneuploidy was found, as analysed by using centromere probes for chromosomes 3, 18 and $X$ (Fig. 1d).

FISH analysis was also performed on the breast cancer cell lines MDA-MB-231, MDA-MB-415, HS 578T and ZR-75-1, and the immortalised mammary epithelial cell line hTERTHME1. Increased copy number of LRIG1 was found in three of the five cell lines (MDA-MB-231, HS 578T and hTERTHME1), whereas decreased copy number was found in the MDA-MB-415 cell line. A normal FISH signal pattern for LRIG1 was present in ZR-75-1.

\section{Quantitative RT-PCR}

Quantitative RT-PCR was performed on RNA extracted from tumour tissue and non-neoplastic tissue from seven of the nine patients in group B (the quality of the samples from two of the patients was not adequate for quantitative RT-PCR analysis). A fibroadenosis was also examined, with collected pieces both from the fibroadenosis and the surrounding tissue. The expression levels in different parts of the healthy breast tissue from the same individual did not differ by more than $20 \%$ (data not shown) and, therefore, a $20 \%$ cut-off level was used for both overexpression and underexpression. The ratio between the expression in the tumour and non-neoplastic tissue was calculated and ratios $>1.2$ were regarded as significant
Figure 1
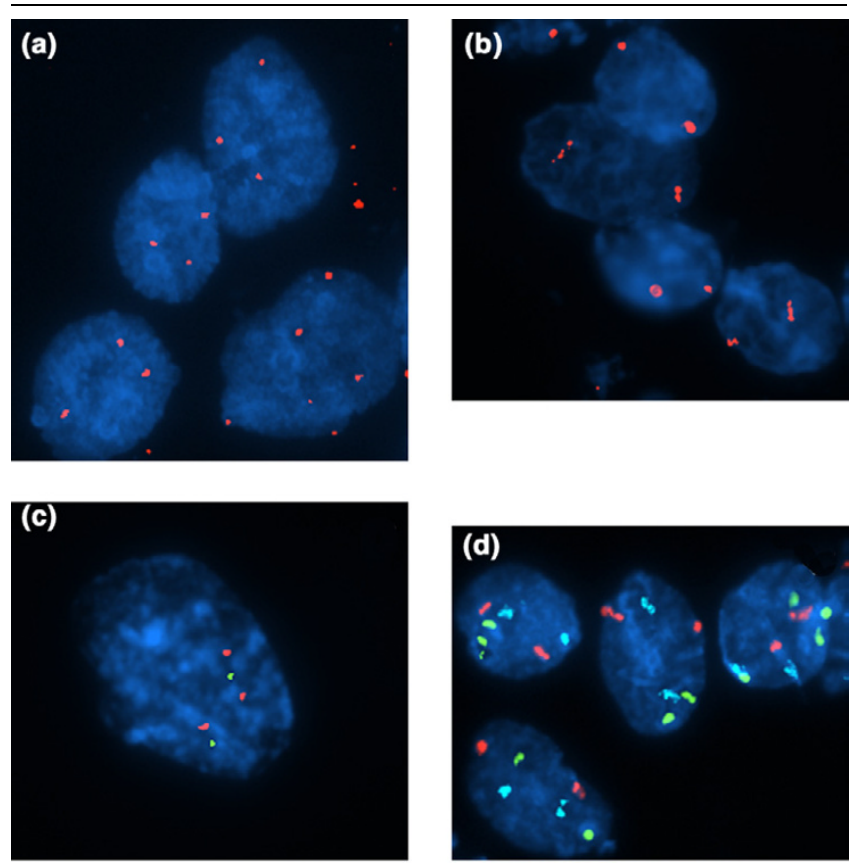

FISH analysis of breast cancer cells from patient B8. (a) Analysis with a specific $L R I G 1$ (red) probe showing increased gene copy number (more than two copies) of the LR/G1 gene at 3p14. (b) Analysis with a specific CEP3 (centromeric chromosome 3; red) probe, showing no additional chromosome 3. (c) Analysis with a specific 3p subtelomeric probe (green) and $L R / G 1$ (red) mixture showing increased gene copy number of the LRIG1 gene but only two copies of the 3p arm. (d) Analysis with a mixture of probes for CEP3 (red), $X$ chromosome (green) and chromosome 18 (blue), showing no aneuploidy for these chromosomes.

tumour overexpression and ratios $<0.8$ were regarded as significant tumour underexpression. LR/G1 mRNA was significantly overexpressed in two of the seven tumours and significantly underexpressed in two of the seven tumours (Table 3). The three tumours with increased LRIG1 copy number (FISH analysis) that were able to be analysed by RTPCR for LRIG1 showed significant overexpression of $L R I G 1$ mRNA in two cases. Four tumours with increased $L R / G 1$ copy number were analysed by RT-PCR for EGFR/ERBB1, and all four showed significantly lower expression of EGFR/ERBB1 and three showed significantly higher expression of ERBB2 than their matched normal controls (Table 4). Two of the 
Table 3

\begin{tabular}{|c|c|c|c|}
\hline Patient no. & $\mathrm{FISH}^{\mathrm{a}}$ & Western blot ${ }^{\mathrm{b}}$ & LRIG1 RT-PCR (T/NN) \\
\hline B1 & I & $\ln$ & $1.45^{d}$ \\
\hline$B 2^{e}$ & I & $\ln$ & - \\
\hline $\mathrm{B} 3^{\mathrm{e}}$ & NL & $\mathrm{E}$ & - \\
\hline B4 & NL & $\mathrm{D}$ & 0.85 \\
\hline B5 & I & $\ln$ & $1.63^{d}$ \\
\hline B6 & NL & $\mathrm{E}$ & $0.50^{d}$ \\
\hline B7 & NL & $\ln$ & $0.36^{d}$ \\
\hline B8 & 1 & $\ln$ & 1.13 \\
\hline B9 & $\mathrm{NL}$ & $\mathrm{E}$ & 1.17 \\
\hline
\end{tabular}

aFISH: I, increased $L R / G 1$ copy number; NL, normal $L R / G 1$ copy number. bWestern blot: comparison of the staining in tumour tissue (T) and nonneoplastic tissue (NN). A visual increase (In)/decrease (D) of at least $50 \%$ was considered convincing. E, equal levels of protein. CLRIG1 RT-PCR T/NN; LRIG1 mRNA expression level in neoplastic (T) tissue samples divided by levels in matched non-neoplastic (NN) tissue samples. dAs described in the results, at p.9, ratios $>1.2$ are regarded as significant overexpression and ratios $<0.8$ are regarded as significant underexpression in neoplastic tissue compared to non-neoplastic tissue. Samples were consecutively collected. eTwo tumours did not yield RNA of sufficient quality for the RT-PCR analysis.

tumours without increased $L R I G 1$ copy number also had lowered EGFR expression.

\section{Western blot analysis of fresh tumour samples and their matched non-neoplastic breast tissue}

In group B, five of the nine tumours overexpressed the LRIG1 protein compared to their matched non-neoplastic tissues as analysed by western blotting. Four of these five tumours also displayed increased LRIG1 copy number (Fig. 2, Table 3). Thus, all of the tumours with increased LRIG1 copy number overexpressed LRIG1 as determined by western blot analysis, but also one tumour with normal LRIG1 copy number showed high levels of the protein by western blotting.

\section{Combined analysis of group A and B}

In total, 28 breast tumours were analysed by FISH with LRIG1 specific probe. A normal signal pattern, corresponding to two LRIG1 copies per nucleus, was detected in 16 cases. In 11 out of 28 tumours (39\%), an increased number of LRIG1 signals were found (Table 2, Fig. 1a). The fraction of tumour cells with increased copy number varied between $21 \%$ and $79 \%$. Complementary FISH analyses showed that there was no increase in the copy number of the entire $3 p$ arm (Fig. 1b-d). As seen by quantitative RT-PCR analysis, two out the three analysed tumours with increased $L R / G 1$ copy number (in group $B$ ) showed higher expression of $L R / G 1$ mRNA than the matched non-neoplastic breast tissues. In all four tumours with increased LRIG1 copy number, expression of LRIG1 protein was higher than in the matched non-neoplastic breast tissue, as assessed by western blot analysis.
Complementary analysis of five transformed breast cancer cell lines showed similar results, with three of them showing an increased copy number of the 3p14 locus.

\section{Discussion}

This novel investigation of $3 p 14$ demonstrated unexpectedly an increased copy number of the proposed tumour suppressor gene $L R / G 1$ in $39 \%(11 / 28)$ of the breast tumours and in $60 \%(3 / 5)$ of the breast cancer cell lines. The malignant process is believed to be driven by genetic diversification through mutations, deletions and amplifications followed by natural selection of surviving and proliferating cancer cells. One result of this process is the enrichment of amplicons harbouring tumour promoting genetic elements, that is, cancer associated genes. Accordingly, the presented results imply that a common, but hitherto unrecognised, breast cancer related gene was located within an amplicon that included the $L R / G 1$ locus at $3 p 14$.

Despite numerous genetic studies, increased copy number at the 3p14 locus has, to our knowledge, never previously been reported in primary human breast tumours. Interestingly, however, amplifications at 3p14 have recently been reported in breast cancer-derived cell lines [29,30]. Previous comparative genomic hybridisation (CGH) studies of $3 p$ have generally shown losses and only rarely gains [31]. There are at least four possible explanations why the herein demonstrated increased copy number at $3 p 14$ has not previously been described. First, the area of increased copy number could be relatively small, and so escaped detection by conventional analyses. Second, most studies of this chromosomal area have analysed $\mathrm{LOH}$, and thus have not addressed possible gene amplifications. Third, results obtained by conventional CGH, a method fre- 
Figure 2

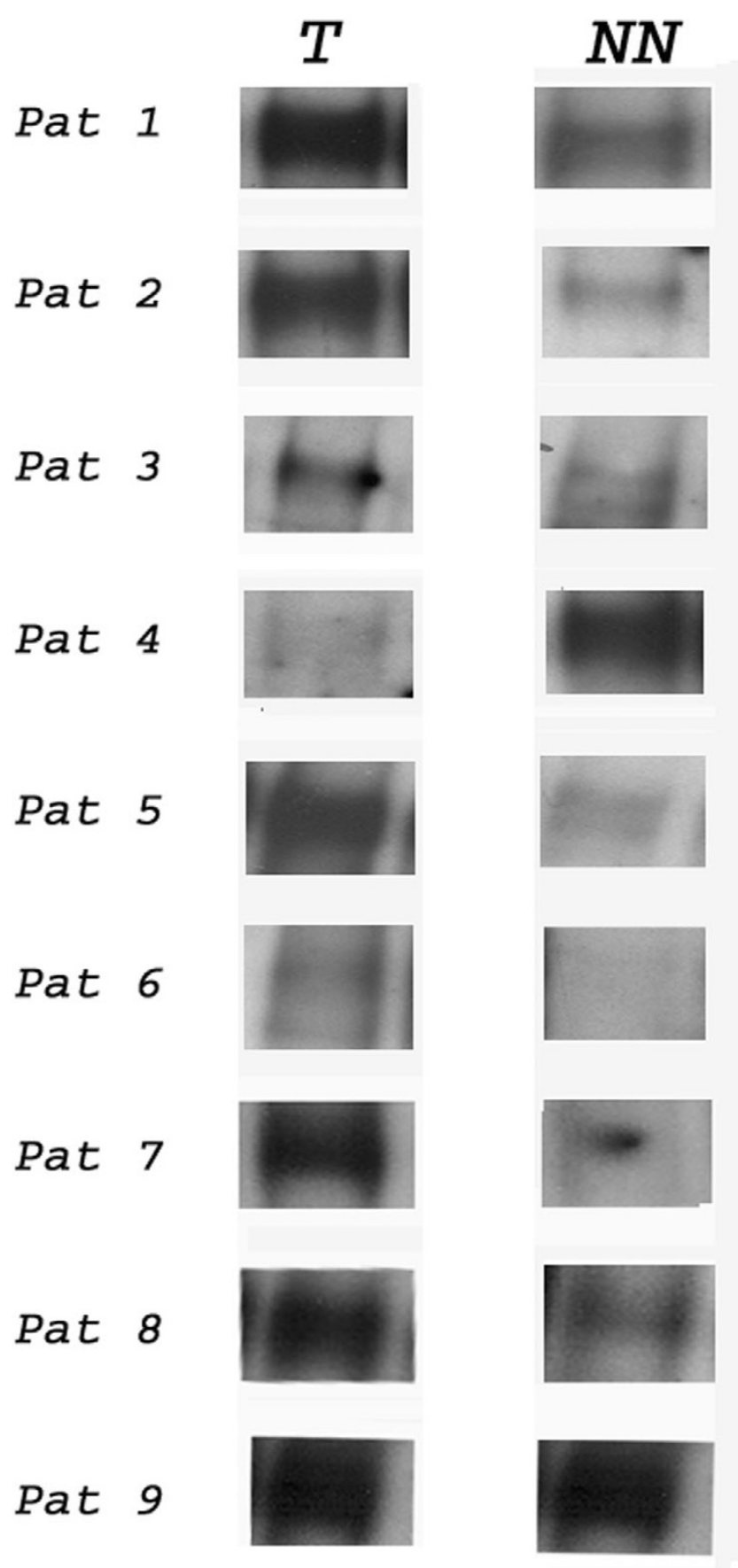

Western blot analyses of LRIG1 in the nine breast cancer patients in group B. Tumours (T) versus non-neoplastic breast tissue (NN). Western blot analysis was performed on samples with primary antibodies LRIG1-151 and anti-rabbit anti-actin. A visual change of at least $50 \%$ was considered convincing, as determined by three different investigators. Pat, patient number. quently used to detect both gains and losses, are usually difficult to interpret in chromosomal regions close to the centromere, such as the LRIG1 locus at 3p14. By employing an alternative $\mathrm{CGH}$ methodology using cDNA arrays, an amplicon at 3p14 was described in breast cancer-derived cell lines [29]. Whether this region is co-duplicated with LRIG1 at 3p14 has not been addressed but will be the subject of future studies. Finally, a further limitation of conventional and array based $\mathrm{CGH}$ methodologies is that they evaluate the mean gene copy number in the analysed sample. FISH, in contrast, has single cell resolution and, thus, is more sensitive and able to detect modest gene copy number changes that could involve only a minority of the tumour cells.

An important question regarding the herein discovered amplicon is its size and the identity of the underlying possible breast cancer gene(s). We have shown by FISH that the area of increased copy number contained LRIG1 at 3p14 but was lacking the centromere and the subtelomeric region of chromosome 3 . In addition, as discussed above, chromosome 3 has previously been extensively studied by $\mathrm{CGH}$, which rules out the possibility of a common amplicon spanning centromere-distal regions of $3 p$. From this, we estimate that the putative breast cancer gene is located on chromosome 3, somewhere between the centromere and 3p21. Obviously, the only gene directly demonstrated so far to be duplicated in the analysed breast tumours was $L R / G 1$. This raises the question of whether LRIG1 itself is a breast cancer gene. LRIG1 has been proposed to interact with and counteract the effects of growth factor receptors such as EGFR/ERBB1 [23,32], thereby functioning as a tumour suppressor. This hypothesis was recently confirmed by molecular studies showing that LRIG1 downregulates ERBB1-4 by enhancing receptor degradation [25,26]. Because EGFR/ERBB1 and ERBB2 are important and frequently overexpressed breast cancer genes, it is unlikely that LRIG1, as an ERBB antagonist, is a tumour promoter. Of course, we cannot exclude that LRIG1 might have other functions, which for tumour promotion could dominate over its ERBB-antagonising effects. According to a recent estimate [33], however, there are 80 genes in addition to $L R / G 1$ in the region between the centromere and 3p21 (coordinates 64M-92M), the gene copy numbers of which could potentially have been increased in conjuction with $L R / G 1$. These genes encode a variety of different kinds of proteins, of known and unknown functions, including a tyrosine kinase receptor (EPHA3), a protein phosphatase regulatory subunit (PPP4R2), an ubiquitin-conjugating enzyme (UBE1C), and different transcription factors (e.g. TMF1, FOXP1 and POU1F1). The amplicon described by Hyman et al. [29] is confined to a $2.7 \mathrm{mb}$ region (coordinates $72 \mathrm{M}-75 \mathrm{M}$ ), which include 13 genes but not $L R / G 1$ at $66 \mathrm{M}$. Moreover, an amplicon close to the $L R / G 1$ locus with the coordinates $60 \mathrm{M}-64 \mathrm{M}$ was recently described in breast cancer cell line MCF-7 [30]. This amplicon contains about 17 genes. Whether the regions at $72 \mathrm{M}-75 \mathrm{M}$ and $60 \mathrm{M}-64 \mathrm{M}$ are increased in copy number in 
Table 4

\begin{tabular}{|c|c|c|c|}
\hline Patient number & $T$ & NN & $\mathrm{T} / \mathrm{NN}^{\mathrm{a}}$ \\
\hline \multicolumn{4}{|l|}{$1^{b}$} \\
\hline EGFR & 4,677 & 12,493 & 0.37 \\
\hline ERBB2 & 24,066 & 21,817 & 1.1 \\
\hline \multicolumn{4}{|l|}{$2^{b}$} \\
\hline EGFR & 3,321 & 14,519 & 0.22 \\
\hline ERBB2 & 61,389 & 6,666 & 9.2 \\
\hline \multicolumn{4}{|l|}{4} \\
\hline EGFR & 20,778 & 14,842 & 1.39 \\
\hline ERBB2 & 9,143 & 6,742 & 1.35 \\
\hline \multicolumn{4}{|l|}{$5^{b}$} \\
\hline EGFR & 9,730 & 15,867 & 0.61 \\
\hline ERBB2 & 13,506 & 3,056 & 4.41 \\
\hline \multicolumn{4}{|l|}{6} \\
\hline EGFR & 1,305 & 15,871 & 0.08 \\
\hline ERBB2 & 10,677 & 10,080 & 1.06 \\
\hline \multicolumn{4}{|l|}{7} \\
\hline EGFR & 1,024 & 12,162 & 0.08 \\
\hline ERBB2 & 7,639 & 5,871 & 1.30 \\
\hline \multicolumn{4}{|l|}{$8^{b}$} \\
\hline EGFR & 4,936 & 28,111 & 0.17 \\
\hline ERBB2 & 17,106 & 9,263 & 1.85 \\
\hline \multicolumn{4}{|l|}{9} \\
\hline EGFR & 5,540 & 1,437 & 3.85 \\
\hline ERBB2 & 7,330 & 5,540 & 1.32 \\
\hline
\end{tabular}

aT/NN: mRNA expression levels of $L R / G 1$ in tumour tissue (T) samples divided by values in matched non-neoplastic (NN) tissue samples. As described in the results, at p.9, ratios $>1.2$ are regarded as significant overexpression and ratios $<0.8$ are regarded as significant underexpression in neoplastic tissue compared to non-neoplastic tissue. bPatients with increased LRIG1 copy number. No RNA from patient 3 was available for EGFR/ERBB2 analysis.

conjunction with the LRIG1 locus at $66 \mathrm{M}$ was not addressed in the present study but will be the subject of future studies. Clearly, a more refined mapping of the area of increased copy number and functional studies of candidate genes are needed for defining the hypothesised breast cancer gene(s). We conclude, nevertheless, that a common but hitherto unrecognised breast cancer gene is located at or near the LRIG1 locus.

Increased LRIG1 copy number as detected by FISH was associated with increased $\mathrm{mRNA}$ and protein levels in tumours compared to non-neoplastic breast tissue, as determined by quantitative RT-PCR and western blot analysis (Table 3). A concordance between gene overexpression and enhanced mRNA levels is often, but not always, observed [29].
Because ERBB family members are strongly implicated in the aetiology of breast cancer, and because ERBB proteins and LRIG1 interact at the molecular level, we analysed the expression of EGFR/ERBB1 and ERBB2 mRNA. Intriguingly, EGFR/ ERBB1 mRNA was significantly underexpressed in all of the four tumours analysed with increased LRIG1 copy number. Of these four tumours, three showed significant overexpression of ERBB2 mRNA. EGFR/ERBB1 is overexpressed in 35\% to $60 \%$ of breast cancers, which correlates with a negative steroid receptor status, increased ERBB2 and VEGF (Vascular endothelial growth factor) expression [7]. The impact of EGFR/ERBB1 overexpression on clinical outcome has not been completely clarified, but in most studies it is considered to be a negative prognostic factor [34]. The combination of increased LRIG1 copy number and protein expression and 
low EGFR/ERBB1 expression might represent a subtype of breast cancer with its own clinical features. To reveal such a biological subtype, a larger number of tumours must be examined.

\section{Conclusion}

We have described, for the first time, frequent increased copy number at $3 p 14.3$ in breast cancer. This attributes a breast cancer associated gene to $3 p 14$ or surrounding plausibly coamplified regions. In future studies, it will be important to define the genetic element, that is, the breast cancer gene(s) underlying the observed copy number increase, and to examine a greater number of tumours in order to evaluate its clinical significance.

\section{Competing interests}

The author(s) declare that they have no competing interests.

\section{Authors' contributions}

IL is a PhD student in the project and participated in the FISH analysis and the overall analysis of the results. IL was also responsible for writing the manuscript. TH participated in the collection of new breast cancer samples and investigating whether the samples were representative. MT carried out the quantitative RT-PCR analysis, YJ carried out the western blot analysis, IG was responsible for the FISH analysis, SE participated in contact with patients for the collection of breast cancer tumours, and KG was responsible for the collection of the breast cancer tumours from 1987 to 1995 . BM, $\mathrm{HH}$ and $\mathrm{RH}$ were responsible for the overall design and implementation of the study and also for the overall analysis of the material and they helped to draft the manuscript. All authors read and approved the final manuscript.

\section{Acknowledgements}

We would like to thank Kerstin Bergh for help with the immunohistochemistry and Charlotte Andersson for help with the FISH analysis. This study was supported by grants from The Swedish Cancer Society and the Cancer Research Foundation, Northern Sweden.

\section{References}

1. Bieche I, Liderau R: Genetic alterations in breast cancer. Genes Chromosomes Cancer 1995, 14:227-251.

2. Ross JS, Linette GP, Stec J, Clark E, Ayers M, Leschly N, Symmans WF, Hortobagyi GN, Pusztai L: Breast cancer biomarkers and molecular medicine. Expert Rev Mol Diagn 2003, 3:573-585.

3. Friedman LS, Ostermeyer EA, Lynch ED, Szabo Cl, Anderson LA, Dowd P, Lee MK, Rowell SE, Boyd J, King MC: The search for BRCA1. Cancer Res 1994, 54:6374-6382.

4. Futreal PA, Liu Q, Shattuck-Eidens D, Cochran C, Harshman K, Tavtigian S, Bennett LM, Haugen-Strano A, Swensen J, Miki Y, et al.: BRCA1 mutations in primary breast and ovarian carcinomas. Science 1994, 266:120-122.

5. Klijn JG, Berns PM, Schmitz PI, Foekens JA: The clinical significance of epidermal growth factor receptor (EGF-R) in human breast cancer: a review on $\mathbf{5 2 3 2}$ patients. Endocr Rev 1992, 13:3-17.

6. Borg A, Tandon AK, Sigurdsson H, Clark GM, Ferno M, Fuqua SA, Killander D, McGuire WL: HER-2/neu amplification predicts poor survival in node-positive breast cancer. Cancer Res 1990, 50:4332-4337.
7. Linderholm BK, Lindh B, Tavelin B, Erlanson M, Beckman L, Grankvist K, Henriksson R: Expression of epidermal growth factor receptor 1 (EGFR1) is correlated with over-expression of $c$ erbB-2, and higher expression of the angiogenic factors basic fibroblast growth factor (BFGF) and vascular endothelial growth factor (VEGF), but do not add prognostic information in primary breast cancer. Breast 2003, 12(suppl 1):S25.

8. Elledge RM, Allred DC: p53 tumor suppressor gene in breast cancer. Breast Cancer Res Treat 1994, 32:39-47.

9. Linderholm BK, Lindahl T, Holmberg L, Klaar S, Lennerstrand J Henriksson R, Bergh J: The expression of vascular endothelial growth factor correlates with mutant p53 and poor prognosis in human breast cancer. Cancer Res 2001, 61:2256-2260.

10. Heimann R, Ferguson DJ, Hellman S: Relationship between $\mathrm{nm} 23$, angiogenesis, and the metastatic proclivity of nodenegative breast cancer. Cancer Res 1998, 58:2766-2771.

11. Nesbit CE, Tersak JM, Prochownik EV: MYC oncogenes and human neoplastic disease. Oncogene 1999, 18:3004-3016.

12. Isola J, Chu L, DeVries S, Matsumura K, Chew K, Ljung BM, Waldman FM: Alterations in ERBB2-amplified breast carcinomas. Clin Cancer Res 1999, 5:4140-4145.

13. Menard S, Pupa SM, Campiglio M, Tagliabue E: Biologic and therapeutic role of HER2 in cancer. Oncogene 2003, 22:6570-6578.

14. Robanus-Maandag EC, Bosch CA, Kristel PM, Hart AA, Faneyte IF, Nederlof PM, Peterse JL, van de Vijver MJ: Association of CMYC amplification with progression from the in situ to the invasive stage in C-MYC-amplified breast carcinomas. J Pathol 2003, 201:75-82.

15. Pandis N, Heim S, Bardi G, Idvall I, Mandahl N, Mitelman : Arm t $(1 ; 16)$ and $i(1 q)$ as sole anomalies identify gain of $1 q$ as a primary chromosomal abnormality in breast cancer. Genes Chromosomes Cancer 1992, 5:235-238.

16. Malamou-Mitsi VD, Syrrou M, Georgiou I, Pagoulatos G, Agnatis $\mathrm{NJ}$ : Analysis of chromosomal aberrations in breast cancer by CGH. Correlations with Histoprognostic Variables and c-erB-2 immunoexpression. J Exp Clin Cancer Res 1999, 18:357-361.

17. Teixeira MR, Pandis N, Bardi G, Andersen JA, Heim S: Karyotypic comparisons of multiple tumorous and macroscopically normal surrounding tissue samples from patients with breast cancer. Cancer Res 1996, 56:855-859.

18. Sato T, Akiyama F, Sakamoto G, Kasumi F, Nakamura Y: Accumulation of genetic alterations and progression of primary breast cancer. Cancer Res 1991, 51:5794-5799.

19. Maitra A, Wistuba II, Washington C, Virmani AK, Ashfaq R, Milchgrub S, Gazdar AF, Minna JD: High-resolution chromosome 3p allelotyping of breast carcinomas and precursor lesions demonstrates frequent loss of heterozygosity and discontinuous pattern of allele loss. Am J Patho/ 2001, 159:119-130.

20. Matsumoto S, Kasumi F, Sakamoto G, Onda M, Nakamura Y, Emi $M$ : Deletion mapping of chromosome arm $3 p$ in breast cancers: a 2-cM region on 3p14.3-21.1 and a 5-cM region on 3p24.3-25.1 commonly deleted in tumours. Genes Chromosomes Cancer 1997, 20:268-274.

21. Yang Q, Nakamura M, Nakamura Y, Yoshimura G, Suzuma T, Umemura T, Shimizu Y, Mori I, Sakurai T, Kakudo K: 2-hit inactivation of FHIT by loss of heterozygosity and hypermethylation in breast cancer. Clin Cancer Res 2002, 8:2890-2893.

22. Ingvarsson $S$, Sigbjornsdottir BI, Huiping $C$, Jonasson JG, Agnarsson BA: Alterations of the FHIT gene in breast cancer: association with tumor progression and patient survival. Cancer Detect Prev 2001, 25:292-298.

23. Nilsson J, Vallbo C, Guo D, Golovleva I, Hallberg B, Henriksson R, Hedman $\mathrm{H}$ : Cloning, characterization and expression of human LIG1. Biochem Biophys Res Commun 2001, 284:1155-1161.

24. Nilsson J, Starefeldt A, Henriksson R, Hedman H: LRIG1 protein in human cells and tissues. Cell Tissue Res 2003, 312:65-71.

25. Gur G, Rubin C, Katz M, Amit I, Citri A, Nilsson J, Amariglio N, Henriksson $\mathrm{R}$, Rechavi $\mathrm{G}$, Hedman $\mathrm{H}$, et al:: LRIG1 restricts growth factor signaling by enhancing receptor ubiquitylation and degradation. EMBO J 2004, 23:3270-3281.

26. Laederich $M B$, Funes-Duran $M$, Yen $L$, Ingalla $E$, Wu $X$, Carraway $\mathrm{KL}$ 3rd, Sweeney C: The leucine-rich repeat protein LRIG1 is a negative regulator of ErbB family receptor tyrosine kinases. $J$ Biol Chem 2004, 279:47050-47056. 
27. Page DL, Dupont WD, Rogers LW, Landenberger M: Intraductal carcinoma of the breast: follow-up after biopsy only. Cancer $1982,49: 751-8$

28. Thomasson M, Hedman H, Guo D, Ljungberg B, Henriksson R: LRIG1 and epidermal growth factor receptor in renal cell carcinoma: a quantitative RT-PCR and immunohistochemical analysis. Br J Cancer 2003, 89:1285-1289.

29. Hyman $E$, Kauraniemi $P$, Hautaniemi $S$, Wolf M, Mousses $S$, Rozenblum E, Ringner M, Sauter G, Monni O, Elkahloun A, et al:: Impact of DNA amplification on gene expression patterns in breast cancer. Cancer Res 2002, 62:6240-6245.

30. Zhao X, Li C, Paez JG, Chin K, Janne PA, Chen TH, Girard L, Minna $J$, Christiani $\mathrm{D}$, Leo $\mathrm{C}$, et al.: An integrated view of copy number and allelic alterations in the cancer genome using single nucleotide polymorphism arrays. Cancer Res 2004, 64:3060-3071.

31. Rennstam K, Ahlstedt-Soini M, Baldetorp B, Bendahl PO, Borg A, Karhu R, Tanner M, Tirkkonen M, Isola J: Patterns of chromosomal imbalances defines subgroups of breast cancer with distinct clinical features and prognosis. A study of $\mathbf{3 0 5}$ tumours by comparative genomic hybridization. Cancer Res 2003, 63:8861-8868.

32. Hedman H, Nilsson J, Guo D, Henriksson R: Is LRIG1 a tumour suppressor gene at chromosome 3p14.3? Acta Oncol 2002, 41:352-354.

33. Map Viewer [http://www.ncbi.nlm.nih.gov/ mapviemaps.cgi? $T A X \mid \mathrm{D}=9606 \& \mathrm{CHR}=3 \& \mathrm{MAPS}=\mathrm{ide}$ ogr,ugHs, genes[64000000.00\%3A92000000.00]\&CMD=TXT]

34. Tsutsui S, Ohno S, Murakami S, Hachitanda Y, Oda S: Prognostic value of epidermal growth factor receptor (EGFR) and its relationship to the estrogen receptor status in 1029 patients with breast cancer. Breast Cancer Res Treat 2002, 71:67-75. 